\title{
Discrimination of Streptomyces albidoflavus Strains Based on the Size and Number of 16S-23S Ribosomal DNA Intergenic Spacers
}

\author{
T. HAIN, N. WARD-RAINEY, $\dagger$ R. M. KROPPENSTEDT, E. STACKEBRANDT, AND F. A. RAINEY* \\ DSMZ-German Collection of Microorganisms and Cell Cultures, D-38124 Braunschweig, Germany
}

\begin{abstract}
In an attempt to develop a rapid and accurate method for discrimination of streptomycetes at the strain level, 21 strains identified by fatty acid analysis as Streptomyces albidoflavus and the type strains of nine subjective synonyms of $S$. albidoflavus were selected for a full or partial $16 \mathrm{~S}$ ribosomal DNA (rDNA) sequence analysis and an investigation of the 16S-23S rDNA intergenic spacer region. 16S rDNA sequence analysis showed that 27 of the strains exhibited $100 \%$ sequence similarity; these strains included the type strain of $S$. albidoflavus and the type strains of the subjective synonyms Streptomyces canescens, Streptomyces coelicolor, Streptomyces felleus, Streptomyces limosus, Streptomyces odorifer, and Streptomyces sampsonii. The type strains of the other subjective synonyms of $S$. albidoflavus (i.e., Streptomyces gougerotii, Streptomyces intermedius, and Streptomyces rutgersensis) were found to have levels of $16 \mathrm{~S}$ rDNA sequence difference of 1.0 to $1.1 \%$ when they were compared to the type strain of $S$. albidoflavus. In order to discriminate between the strains which had identical 16S rDNA sequences, the 16S-23S rDNA intergenic spacer regions were amplified and cloned, and the sequences of the spacer regions were determined for four $S$. albidoflavus strains, including the type strain. The 16S-23S rDNA intergenic spacer region was found to vary in length and sequence composition among the strains and within each strain. The sizes and numbers of 16S-23S rDNA intergenic spacer regions for the 27 strains with identical 16S rDNA sequences were determined by high-resolution electrophoresis of FAM-labeled PCR products and a subsequent size analysis with GeneScan 672 software. This was shown to be a useful method for discrimination of $S$. albidoflavus strains. Strains with the same 16S-23S rDNA intergenic spacer band pattern, as determined by high-resolution electrophoresis of FAM-labeled PCR products, could be further discriminated on the basis of the sequence composition of the spacer region.
\end{abstract}

With 464 validly described species and 45 subspecies (6), the genus Streptomyces currently contains the largest number of species of any genus in the domain Bacteria. The ability of the streptomycetes to produce secondary metabolites, including antibiotics, makes them organisms of great commercial importance and the subject of extensive study by the pharmaceutical industry. Over the years, numerous methods have been applied with the aim of identifying, characterizing, and discriminating between streptomycete strains. The primary aim of such investigations has been to develop the most rapid and accurate method for proving the novelty of newly isolated strains. The methods that have been utilized include numerical analysis of phenotypic characteristics $(12,30)$, fatty acid profiling (25), phage susceptibility studies (14), ribosomal protein sequence analysis (22), restriction fragment length polymorphism analysis $(2,4)$, DNA-DNA hybridization studies (16-19), and 16S ribosomal DNA (rDNA) sequence analysis $(13,21,26,27)$. Each of these methods has been successful to varying degrees, depending on the level of discrimination required. From the numerical taxonomy analyses of phenotypic characteristics (12, 30 ), it is clear that the yellow streptomycetes fall into two main clusters, one containing Streptomyces albidoflavus and related species and the other comprising Streptomyces griseus, Streptomyces anulatus, and related taxa. Such clusters provide ample species and strains for comparative studies. The data made available through such studies allow the selection of representative species groups for study at the strain level.

In the majority of bacterial taxa investigated, the genes coding for components of the rRNA are arranged in the order $16 \mathrm{~S}-23 \mathrm{~S}-5 \mathrm{~S}$, as is found in Escherichia coli (3). The rRNA

\footnotetext{
* Corresponding author.

$\dagger$ Present address: Department of Microbiology, Life Sciences Building, Louisiana State University, Baton Rouge, LA 70803.
}

operon is often found in multiple copies in the bacterial chromosome, and the number of copies ranges from 1 to 14 (31). These genes are usually linked and separated by spacer regions which may vary in length and sequence composition. The length and sequence polymorphisms in such spacers within the rRNA operon have been shown to be useful in discriminating between different bacterial species $(1,8-11)$ and also in the identification of fungal species $(7,28)$. Jensen et al. (10) demonstrated the usefulness of this method for distinguishing certain taxa at the species level by determining size differences in PCR-amplified 16S-23S rDNA spacer fragments.

Here we report the usefulness of $16 \mathrm{~S}-23 \mathrm{~S}$ rDNA intergenic spacer analysis for discrimination of streptomycete strains when the species $S$. albidoflavus was used as an example and demonstrate the use of high-resolution polyacrylamide gel electrophoresis of dye-labeled PCR products as a rapid method for determining spacer size and number.

\section{MATERIALS AND METHODS}

Bacterial strains and culture conditions. The Streptomyces strains used in this study are shown in Table 1 . All of the strains were cultivated on glucose-yeast extract-malt extract agar containing (per liter) $4 \mathrm{~g}$ of yeast extract, $10 \mathrm{~g}$ of malt extract, $4 \mathrm{~g}$ of D-glucose, $2 \mathrm{~g}$ of $\mathrm{CaCO}_{3}$, and $15 \mathrm{~g}$ of agar. Plates were incubated aerobically at $28^{\circ} \mathrm{C}$

DNA extraction. Genomic DNA was isolated and purified as described by Rainey et al. (24).

PCR amplification of the 16S rDNA. Amplification of the 16S rDNA was performed as described previously (24) by using Taq polymerase (Boehringer, Mannheim, Germany) and the following primers: 5' GAGTTTGATCCTGGCT CAG 3' (positions 9 to 27, Escherichia coli numbering [3]) and 5' AGAAAGG AGGTGATCCAGCC $3^{\prime}$ (positions 1525 to 1545 ). A total of 28 cycles of amplification were performed with a model 480 DNA thermal cycler (Perkin-Elmer Cetus, Foster City, Calif.) by using the following thermal profile: $52^{\circ} \mathrm{C}$ for $1 \mathrm{~min}$, $72^{\circ} \mathrm{C}$ for $2 \mathrm{~min}$, and $93^{\circ} \mathrm{C}$ for $1 \mathrm{~min}$. An additional final extension step consisting of $72^{\circ} \mathrm{C}$ for 5 min was performed. The PCR products were purified by extraction with chloroform; this was followed by final purification with a Prep-A-Gene DNA purification kit (Bio-Rad, Hercules, Calif.), used according to the manufacturer's instructions. Elution of DNA was done with $50 \mu \mathrm{l}$ of water. 
TABLE 1. Strains used in this study, numbers of base pairs determined in the 16S rDNAs, and accession numbers of the $16 \mathrm{~S}$ rDNA sequences

\begin{tabular}{|c|c|c|c|}
\hline Taxon & Strain & $\begin{array}{c}\text { No. of } \\
\text { nucleotides } \\
\text { determined }\end{array}$ & $\begin{array}{c}\text { EMBL } \\
\text { accession } \\
\text { no. }\end{array}$ \\
\hline S. albidoflavus & $\operatorname{DSM} 40455^{\mathrm{T}}$ & 1,476 & Z76676 \\
\hline S. albidoflavus & DSM 40792 & 1,476 & Z76677 \\
\hline S. albidoflavus & DSM 40880 & 1,476 & Z76683 \\
\hline S. albidoflavus & DSM 46452 & 1,476 & Z76685 \\
\hline S. canescens & DSM $40001^{\mathrm{T}}$ & 1,476 & Z76684 \\
\hline S. coelicolor & DSM $40233^{\mathrm{T}}$ & 1,476 & Z76678 \\
\hline S. felleus & DSM $40130^{\mathrm{T}}$ & 1,476 & Z76681 \\
\hline S. gougerotii & DSM $40324^{\mathrm{T}}$ & 1,476 & Z76687 \\
\hline$S$. intermedius & DSM $40372^{\mathrm{T}}$ & 1,474 & Z76686 \\
\hline S. limosus & DSM $40131^{\mathrm{T}}$ & 1,476 & Z76679 \\
\hline S. odorifer & DSM $40347^{\mathrm{T}}$ & 1,476 & Z76682 \\
\hline S. rutgersensis & DSM $40077^{\mathrm{T}}$ & 1,476 & Z76688 \\
\hline S. sampsonii & DSM $40394^{\mathrm{T}}$ & 1,476 & Z76680 \\
\hline S. albus & DSM 40890 & 870 & Z76689 \\
\hline S. cellulosae & DSM 40802 & 870 & Z76690 \\
\hline S. coelicolor & DSM 40624 & 870 & Z76691 \\
\hline S. coelicolor & DSM 40665 & 870 & Z76692 \\
\hline S. coelicolor & DSM 40674 & 870 & Z76693 \\
\hline S. coelicolor & DSM 40675 & 870 & Z76694 \\
\hline S. coelicolor & DSM 40678 & 870 & Z76695 \\
\hline S. coelicolor & DSM 40679 & 870 & Z76696 \\
\hline S. coelicolor & DSM 40681 & 870 & Z76697 \\
\hline S. coelicolor & DSM 40682 & 870 & Z76698 \\
\hline S. coelicolor & DSM 40683 & 870 & Z76699 \\
\hline S. griseus & DSM 40882 & 870 & Z76700 \\
\hline Streptomyces sp. & DSM 40485 & 870 & Z76701 \\
\hline Streptomyces sp. & DSM 40557 & 870 & Z76702 \\
\hline Streptomyces sp. & DSM 40691 & 870 & Z76703 \\
\hline Streptomyces sp. & DSM 40770 & 870 & Z76704 \\
\hline Streptomyces sp. & DSM 40869 & 870 & Z76705 \\
\hline
\end{tabular}

PCR amplification and cloning of the 16S-23S rDNA intergenic spacer region. The 16S-23S rDNA intergenic spacer region was amplified by PCR as described above, except that the primers used were $5^{\prime}$ TACACACGTGCTACAATG 3' (positions 1224 to 1242 in $16 \mathrm{~S}$ rDNA; E. coli numbering) and $5^{\prime}$ (G/T)TTCGC TCGCC(A/G)CTAC 3' (positions 241 to 255 in $23 \mathrm{~S}$ rDNA). The PCR products were cloned by using a pCR-Script cloning kit (Stratagene, La Jolla, Calif.) according to manufacturer's instructions.

Sequence determination and comparison. The $16 \mathrm{~S}$ rDNA PCR products were partially sequenced directly by using a Taq DyeDeoxy terminator cycle sequencing kit (Applied Biosystems, Foster City, Calif.) and a model 480 DNA thermal cycler (Perkin-Elmer Cetus) according to the manufacturer's recommendations. The sequencing primers used were $5^{\prime} \mathrm{G}(\mathrm{T} / \mathrm{A}) \mathrm{ATTACCGCGGC(T/G)GCTG} 3^{\prime}$ (primer 519r) and 5' ATTAGATACCCTGGTAG 3' (primer 803f) in the case of partial sequences. Complete $16 \mathrm{~S}$ rDNA sequences were determined by using the primers described previously (24). Cloned 16S-23S rDNA spacer regions were first amplified by PCR from the cloning vector by using the conditions described above and primers M13f (5' GTAAAACGACGGCCAGT $\left.3^{\prime}\right)$ and M13r $\left(5^{\prime}\right.$ GGAAACAGCTATGACCATG $3^{\prime}$ ). Sequencing of the PCR products was performed as described above by using the $23 \mathrm{~S}$ rDNA primer binding at positions 241 to 255 (see above) and primer 5' G(A/G)GCCTTG(C/T)ACACACCG 3' (positions 1382 to 1401 in $16 \mathrm{~S}$ rDNA, E. coli numbering). Purified sequence reaction mixtures were electrophoresed with an Applied Biosystems model 373A DNA sequencer.

The 16S rDNA sequences were aligned manually by using the ae 2 editor of the Ribosomal Database Project (20). All of the positions determined in the partial and full sequences were used for pairwise similarity comparisons. 16S-23S rDNA intergenic spacer sequences were manually aligned with each other on the basis of the highly conserved regions.

16S-23S rDNA intergenic spacer fragment size analysis. $\mathrm{PCR}$ amplification of the 16S-23S rDNA intergenic spacer for use in fragment size analysis was carried out as described above, except that we used a FAM-labeled (Applied Biosystems) primer binding to the $3^{\prime}$ terminus of the $16 \mathrm{~S} \mathrm{rDNA}, 5^{\prime} \mathrm{G}(\mathrm{T} / \mathrm{C}) \mathrm{TGGATC}$ ACCTCC(T/C)TTC3' (positions 1526 to 1543), and an unlabeled primer binding to the $5^{\prime}$ terminus of the 23S rDNA, 5' GCGCCCTTAAAAACTTGG 3' (positions 3 to 20 ). The following thermal profile was used: $30 \mathrm{~s}$ at $48^{\circ} \mathrm{C}, 1 \mathrm{~min}$ at $72^{\circ} \mathrm{C}$, and $30 \mathrm{~s}$ at $94^{\circ} \mathrm{C}$ for 25 cycles and a final cycle consisting of $10 \mathrm{~min}$ at $72^{\circ} \mathrm{C}$. The PCR products were diluted 1:50 with sterile water, and $1.2 \mu \mathrm{l}$ of each dilu- tion was added to $1.8 \mu \mathrm{l}$ of a ROX-labeled internal lane standard (GENESCAN2500 ROX; Applied Biosystems) premixture, which was prepared as recommended by the manufacturer. The $3-\mu \mathrm{l}$ samples were denatured for $2 \mathrm{~min}$ at $90^{\circ} \mathrm{C}$ and placed on ice. The samples were electrophoresed on a $6 \%(\mathrm{wt} / \mathrm{vol})$ polyacrylamide gel (length, $12 \mathrm{~cm}$ ) containing $8 \mathrm{M}$ urea and $1 \times$ Tris-borate-EDTA by using an Applied Biosystems model 373A DNA sequencer and the following conditions: $2,500 \mathrm{~V}, 45 \mathrm{~mA}$, and $30 \mathrm{~W}$ for $4 \mathrm{~h}$. Fragment sizes were determined by using GENESCAN 672 software (Applied Biosystems) by comparison with the ROX-labeled internal lane standard (GENESCAN-2500 ROX; Applied Biosystems).

Nucleotide sequence accession numbers. The complete 16S rDNA sequences determined in this study have been deposited in EMBL database under accession numbers Z76676 to Z76688 (Table 1). The partial 16S rDNA sequences determined in this study have been deposited in EMBL database under accession numbers Z76689 to Z76705. The $16 \mathrm{~S}-23 \mathrm{~S}$ rDNA intergenic spacer region sequences of $S$. albidoflavus DSM $40455^{\mathrm{T}}$ ( $\mathrm{T}=$ type strain) and DSM 40792 have been deposited in EMBL database under accession numbers Z77332 to Z77351.

\section{RESULTS AND DISCUSSION}

16S rDNA sequence comparison. Strains of $S$. albidoflavus, a polyene antifungal antibiotic producer (23), were chosen for comparison in this study. Thirty Streptomyces strains were selected for analysis. These included the four S. albidoflavus strains listed in the Deutsche Sammlung von Mikroorganismen und Zellkulturen GmbH Catalogue of Strains (5), members of nine species considered to be subjective synonyms of $S$. albidoflavus (29), and 18 strains identified as $S$. albidoflavus strains on the basis of fatty acid profile analysis (15) although they were identified as members of other species by the original isolaters or depositors (5).

Partial 16S rDNA sequence data covering the most variable regions in streptomycetes, the $\gamma, \alpha$, and $\beta$ regions (26), were obtained for all 30 strains. In the two stretches sequenced (positions 32 to 499 and 829 to 1249, E. coli numbering [3]), which comprised 870 nucleotide positions, there was $100 \% 16 \mathrm{~S}$ rDNA sequence similarity among 27 of the 30 strains, including the type strain of $S$. albidoflavus, strain DSM 40455. Full $16 \mathrm{~S}$ rDNA sequence data for 1,474 to 1,476 nucleotide positions were determined for the four $S$. albidoflavus strains (strains DSM 40455 ${ }^{\mathrm{T}}$, DSM 40792, DSM 40880, and DSM 46452) and the nine subjective synonyms. A comparison of the sequences showed that 10 of these 13 strains, including six of the nine subjective synonyms, were identical both in the most variable regions $(\gamma, \alpha$, and $\beta$ regions) and in the remaining conserved regions for the 1,474 nucleotide positions determined. Three of the subjective synonyms, Streptomyces intermedius DSM $40372^{\mathrm{T}}$, Streptomyces gougerotii DSM $40324^{\mathrm{T}}$, and Streptomyces rutgersensis DSM $40077^{\mathrm{T}}$, exhibited 1.0 to $1.1 \%$ sequence differences over the 1,474 nucleotide positions compared to the type strain of S. albidoflavus, strain DSM 40455. These data support the findings of Williams et al. (29), who reported that Streptomyces canescens, Streptomyces coelicolor, Streptomyces felleus, Streptomyces limosus, Streptomyces odorifer, and Streptomyces sampsonii are subjective synonyms of $S$. albidoflavus. However, the levels of $16 \mathrm{~S}$ rDNA sequence difference between three of the strains, $S$. intermedius DSM $40372^{\mathrm{T}}, S$. gougerotii DSM $40324^{\mathrm{T}}$, and S. rutgersensis DSM $40077^{\mathrm{T}}$, and type strain DSM 40455 of $S$. albidoflavus (1.0 to $1.1 \%$ ) cast doubt on the status of these species as subjective synonyms of $S$. albidoflavus; recent DNA-DNA hybridization data for these species and $S$. albidoflavus DSM $40455^{\mathrm{T}}$ confirm this finding (17). S. intermedius DSM $40372^{\mathrm{T}}, S$. gougerotii DSM $40324^{\mathrm{T}}$, and $S$. rutgersensis DSM $40077^{\mathrm{T}}$ show between 99.8 and $100 \% 16 \mathrm{~S}$ rDNA sequence similarity to each other. As more $16 \mathrm{~S}$ rDNA sequence data become available for additional species of the genus Streptomyces, the true species identity of these strains should become clear. These three species were not investigated further in this study. 


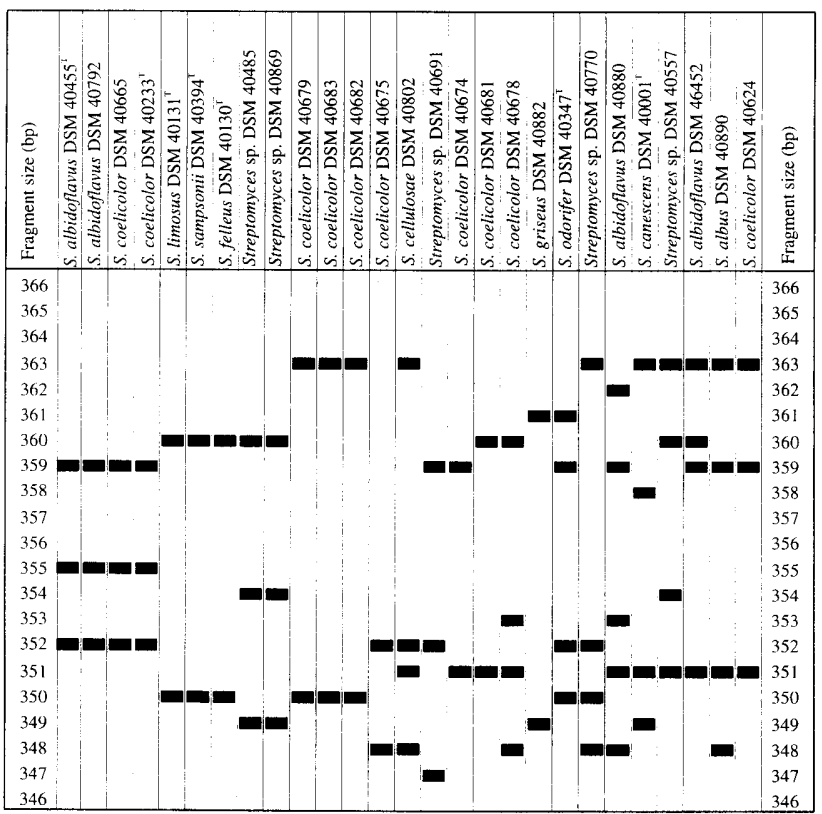

FIG. 1. Diagram of the 16S-23S rDNA intergenic spacer region band patterns of dye-labeled PCR-generated fragments. The sizes of the fragments were determined by using the GENESCAN 672 software (Applied Biosystems).

16S-23S rDNA intergenic spacer region sequence comparison. Direct sequencing of the PCR products of the $16 \mathrm{~S}-23 \mathrm{~S}$ rDNA intergenic spacer regions of four $S$. albidoflavus strains (DSM 40455 $5^{\mathrm{T}}$, DSM 40792, DSM 40880, and DSM 46452) yielded unreadable mixed sequence data, indicating that heterogeneous sequences were present in a single PCR product. In order to determine the extent of sequence heterogeneity, the PCR products were cloned prior to sequencing. A comparison of the $16 \mathrm{~S}-23 \mathrm{~S}$ rDNA intergenic spacer region clone sequences showed that they vary in number, size, and composition within and between the four strains.

The extent of sequence length heterogeneity between and within the four $S$. albidoflavus strains investigated suggested that these strains could be discriminated on the basis of spacer length and/or sequence composition. The application of this observation to discrimination of streptomycete strains required the development of a rapid and accurate method for determining the number and size of the 16S-23S rDNA intergenic spacer fragments. PCR fragments which differ in length by $<10$ bp cannot be readily resolved by normal agarose gel electrophoresis. Cloning and sequencing of 16S-23S rDNA spacer regions on a routine basis would be both costly and timeconsuming. High-resolution polyacrylamide gel electrophoresis as used by Jensen et al. (10) provides a method to separate such fragments. In this study we used high-resolution polyacrylamide gel electrophoresis of dye-labeled spacer fragments and GENESCAN 672 software for rapid and accurate determination of fragment size and number.

16S-23S rDNA intergenic spacer region fragment size analysis. Dye-labeled amplification products of the 16S-23S rDNA intergenic spacer region were generated for the 27 strains shown to have identical $16 \mathrm{~S}$ rDNA sequences. Electrophoresis and fragment size analysis of these products revealed extensive variability in the number and size of spacer regions and resulted in 19 distinct band patterns (Fig. 1). The number of bands ranged from two to five, and the band sizes were between 347 and 363 bp (including the length of amplification primers). The GENESCAN 672 software calculates fragment size to two decimal places. However, in this study we approximated the values to the nearest whole number. The process of amplification, electrophoresis, and size calculation was repeated three times for each strain. The greatest variation found between replicates was $0.5 \mathrm{bp}$. The method can therefore be considered highly reproducible, and the patterns obtained in different experiments are comparable. When this approach was used, strains which have been found to have identical partial or complete $16 \mathrm{~S}$ rDNA sequences could in many cases be discriminated at a lower level on the basis of the band pattern.

Of the 19 different band patterns, 4 were exhibited by more than one strain (Fig. 1). The presence of identical band patterns in these strain groups may indicate that the strains are identical. However, a sequence analysis of the cloned spacer regions indicated that a band of a particular size may represent more than one sequence with the same number of nucleotides but different sequence compositions. This was demonstrated for strains DSM $40455^{\mathrm{T}}$ and DSM 40792, which had identical band patterns but differed in sequence type within each strain. Ten clones of each strain were randomly chosen, and the inserts were sequenced. The sequences of the $16 \mathrm{~S}-23 \mathrm{~S}$ rDNA intergenic spacers were between 311 and 322 nucleotides long and contained six highly conserved regions and five variable regions (Fig. 2 and Table 2). Highly conserved regions $\mathrm{c} 1$ to $\mathrm{c} 6$ were $15,68,20,31,19$, and 49 nucleotides long, respectively. For each of the five variable regions, regions v1 to v5, more than one sequence composition was found. In the case of variable regions v1 (19 to 28 nucleotides long) and v5 (29 to 32 nucleotides long) three different sequence compositions were determined. Variable regions v 2 and v 3 were 21 and 27 nucleotides long, respectively, while v4 was either 11 or 12 nucleotides long. In addition, more than one sequence type consisting of combinations of different variable regions was found within each strain. From the sequence data for 10 clones of $S$. albidoflavus DSM $40455^{\mathrm{T}}$, four different spacer sequences were identified, while eight different sequences were found among 10 clones of $S$. albidoflavus DSM 40792. In all, 10 different types were found within the two strains. Two sequence types were found in both strains, while two sequence types were found to be unique to strain DSM $40455^{\mathrm{T}}$ and six were unique to strain DSM 40792.

Conclusions. $16 \mathrm{~S}$ rDNA sequence analysis, which was previously shown to be useful for differentiating Streptomyces species, was found to be of no value for discriminating $S$. albidoflavus strains. This study demonstrates the usefulness of the 16S-23S rDNA intergenic spacer region for discrimination at the strain level. By using the combination of dye-labeled PCRgenerated 16S-23S rDNA intergenic spacer fragments and the accurate size determination facility of the GENESCAN 672 software, it is possible to produce strain-specific band patterns even when fragments differ in size by only a few base pairs. From the 16S-23S rDNA intergenic spacer sequence data obtained for two $S$. albidoflavus strains as described above, and given that strain-specific sequences were observed, it should be possible to design strain-specific oligonucleotide probes or PCR primers which could be used both for identification and for environmentally oriented studies. The high reproducibility

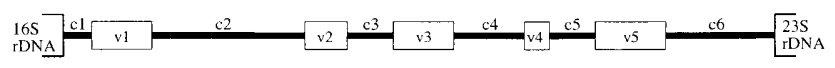

FIG. 2. 16S-23S rDNA intergenic spacer region of S. albidoflavus strains. The spacer region contains six highly conserved regions (regions $\mathrm{c} 1$ to $\mathrm{c} 6$ ) and five variable regions (regions v1 to v5), as determined by sequence analysis. 




and high throughput potential of the $16 \mathrm{~S}-23 \mathrm{~S}$ rDNA intergenic spacer fragment size analysis method has far-reaching implications for the establishment of a database for strains of various Streptomyces species. The method may also have applications within other actinomycete groups or across the broad bacterial spectrum.

\section{REFERENCES}

1. Barry, T., G. Colleran, M. Glennon, L. K. Dunican, and F. Gannon. 1991 The $16 \mathrm{~S} / 23 \mathrm{~S}$ ribosomal spacer region as a target for DNA probes to identify eubacteria. PCR Methods Applic. 1:51-56.

2. Beyazova, M., and M. P. Lechevalier. 1993. Taxonomic utility of restriction endonuclease fingerprinting of large DNA fragments from Streptomyces strains. Int. J. Syst. Bacteriol. 43:674-682.

3. Brosius, J., T. J. Dull, D. D. Sleeter, and H. F. Noller. 1978. Gene organisation and primary structure of a ribosomal RNA operon from Escherichia coli. J. Mol. Biol. 148:107-127.

4. Clarke, S. D., D. A. Ritchie, and S. T. Williams. 1993. Ribosomal DNA restriction fragment analysis of some closely related Streptomyces species. Syst. Appl. Microbiol. 16:256-260.

5. DSM-Deutsche Sammlung von Mikroorganismen und Zellkulturen GmbH. 1993. Catalogue of strains, 5th ed. DSM-Deutsche Sammlung von Mikroorganismen und Zellkulturen GmbH, Braunschweig, Germany.

6. DSMZ-Deutsche Sammlung von Mikroorganismen und Zellkulturen GmbH 1996. Bacterial nomenclature up-to-date April 1996. DSMZ-Deutsche Sammlung von Mikroorganismen und Zellkulturen $\mathrm{GmbH}$, Braunschweig, Germany.

7. Gardes, M., T. J. White, J. A. Fortin, T. D. Bruns, and J. W. Taylor, 1991 Identification of indigenous and introduced symbiotic fungi in ectomycorrhizae by amplification of nuclear and mitochondrial DNA. Can. J. Bot 69:180-190

8. Gürtler, V., and H. D. Barrie. 1995. Typing of Staphylococcus aureus by PCR-amplification of variable length $16 \mathrm{~S}-23 \mathrm{~S}$ rDNA spacer regions: characterization of spacer sequences. Microbiology 141:1255-1265.

9. Gürtler, V., and V. A. Stanisich. 1996. New approaches to typing and identification of bacteria using the $16 \mathrm{~S}-23 \mathrm{~S}$ rDNA spacer region. Microbiology 142:3-16.

10. Jensen, M. A., J. A. Webster, and N. Straus. 1993. Rapid identification of bacteria on the basis of polymerase chain reaction-amplified ribosomal DNA spacer polymorphisms. Appl. Environ. Microbiol. 59:945-952.

11. Ji, Y., K. E. Kempsell, M. J. Colston, and R. A. Cox. 1994. Nucleotide sequences of the spacer-1, spacer-2 and trailer regions of the $r m$ operons and secondary structures of precursor 23S rRNAs and precursor 5S rRNAs of slow-growing mycobacteria. Microbiology 140:1763-1773.

12. Kämpfer, P., R. Kroppenstedt, and W. Dott. 1991. A numerical classification of the genera Streptomyces and Streptoverticillium using miniaturized physiological tests. J. Gen. Microbiol. 137:1831-1891.

13. Kim, D., J. Chun, N. Sahin, Y. C. Hah, and M. Goodfellow. 1996. Analysis of thermophilic clades within the genus Streptomyces by $16 \mathrm{~S}$ ribosomal DNA sequence comparisons. Int. J. Syst. Bacteriol. 46:581-587.

14. Korn, F., B. Weingartner, and H. J. Kutzner. 1978. A study of twenty actinophages: morphology, serological relationships and host range, p. 251270. In E. Freerksen, I. Tarnok, and J. H. Thumin (ed.), Genetics of the Actinomycetales. Gustav Fischer Verlag, Stuttgart, Germany.

15. Kroppenstedt, R. M. 1996. Unpublished data.

16. Labeda, D. 1993. DNA relatedness among strains of the Streptomyces lavendulae phenotypic cluster group. Int. J. Syst. Bacteriol. 43:822-825.

17. Labeda, D. 1996 . Unpublished data.

18. Labeda, D., and A. J. Lyons. 1991. Deoxyribonucleic acid relatedness among species of the "Streptomyces cyaneus" cluster. Syst. Appl. Microbiol. 14:158164.

19. Labeda, D., and A. J. Lyons. 1991. The Streptomyces violaceusniger cluster is heterogeneous in DNA relatedness among strains: emendation of the descriptions of $S$. violaceusniger and Streptomyces hygroscopicus. Int. J. Syst. Bacteriol. 41:398-401.

20. Maidak, B. L., N. Larsen, M. J. McCaughey, R. Overbeck, G. J. Olsen, K. Fogel, J. Blandy, and C. R. Woese. 1994. The Ribosomal Database Project. Nucleic Acids Res. 22:3483-3487.

21. Mehling, A., U. F. Wehmeier, and W. Piepersberg. 1995. Nucleotide se quences of streptomycete $16 \mathrm{~S}$ ribosomal DNA: towards a specific identification system for streptomycetes using PCR. Microbiology 141:2139-2147.

22. Ochi, K. 1995. A taxonomic study of the genus Streptomyces by analysis of ribosomal protein AT-L30. Int. J. Syst. Bacteriol. 45:507-514.

23. Pridham, T. G., and A. J. Lyons. 1976. Polyenic antifungal antibiotics: systematics of producers, p. 373-541. In T. Arai (ed.), Actinomycetes: the boundary microorganisms. Toppan Company Limited, Tokyo, Japan.

24. Rainey, F. A., N. Ward-Rainey, R. M. Kroppenstedt, and E. Stackebrandt. 1996. The genus Nocardiopsis represents a phylogenetically coherent taxon and a distinct actinomycete lineage: proposal of Nocardiopsaceae fam. nov. Int. J. Syst. Bacteriol. 46:1088-1092.

25. Saddler, G. S., A. G. O'Donnell, M. Goodfellow, and D. E. Minnikin. 1987. 
SIMCA pattern recognition in the analysis of streptomycete fatty acids. J. Gen. Microbiol. 133:1137-1147.

26. Stackebrandt, E., D. Witt, C. Kemmerling, R. Kroppenstedt, and W. Liesack 1991. Designation of streptomycete $16 \mathrm{~S}$ and $23 \mathrm{~S}$ rRNA-based target regions for oligonucleotide probes. Appl. Environ. Microbiol. 57:1468-1477.

27. Takeuchi, T., H. Sawada, F. Tanaka, and I. Matsuda. 1996. Phylogenetic analysis of Streptomyces spp. causing potato scab based on 16S rRNA sequences. Int. J. Syst. Bacteriol. 46:476-479.

28. Vilgalys, R., and M. Hester. 1990. Rapid genetic identification and mapping of enzymatically amplified ribosomal DNA from several Cryptococcus species. J. Bacteriol. 172:4238-4246.
29. Williams, S. T., M. Goodfellow, and G. Alderson. 1989. Genus Streptomyces Wakesman and Henrici $1943,339^{\mathrm{AL}}$, p. 2452-2492. In S. T. Williams, M. E. Sharpe, and J. G. Holt (ed.), Bergey's manual of systematic bacteriology, vol. 4. Williams and Wilkins, Baltimore, Md.

30. Williams, S. T., M. Goodfellow, G. Alderson, E. M. H. Wellington, P. H. Sneath, and M. J. Sakin. 1983. Numerical classification of Streptomyces and related genera. J. Gen. Microbiol. 129:1743-1813.

31. Young, M., and S. T. Cole. 1993. Clostridium, p. 35-52. In A. L. Sonenshein, J. A. Hoch, and R. Losick (ed.), Bacillus subtilis and other gram-positive organisms. Biochemistry, physiology, and molecular genetics. American Society for Microbiology, Washington, D.C. 